\title{
Human T-cell lymphotropic virus types 1 and 2 antibodies seroprevalence among blood donors at national public health blood bank, Khartoum- Sudan 2019
}

Babbiker Mohammed Taher Goris ${ }^{1{ }^{1 *}}$

${ }^{1}$ Department of Medical Microbiology, Faculty of Medical Laboratory Sciences, Sudan University of Science and technology, Sudan

\begin{abstract}
The human T-cell lymphotropic virus types 1 and 2 (HTLV 1/2) are well known causes of adult T cell leukemia lymphoma. Both viruses were established to be transmitted through various mode including sexual contact and blood transfusion. This study was aimed to determine the seroprevalence of HTLV-1/2 antibodies among blood donors in Public Health Laboratory. During the period of August 2019 to October 2019 a total of 394 blood samples were obtained from blood donors visiting the Blood bank of National Public Health Laboratory, both males and females were included. The blood samples were analyzed for the presence of anti - HTLV-1,2 by a commercially available enzyme-linked immune-sorbent assay following the instructions of the manufacturer. The study participants were included $361(91.6 \%)$ males and $33(8.4 \%)$ females. The result show that of the 394 blood donors, four (4) were found to be seropositive for HTLV-1 antibodies giving a prevalence of 1.02\%. While all samples were negative for the HTLV-2 antibodies. Among HTLV-1 positive cases 3 were male (75\%) while only one female (25\%) was found to be seropositive for HTLV-1 antibodies. None of the married donors was found to be seropositive for HTLV-1. We conclude that the seroprevalence of HTLV 1/2 were matched to the internationally estimated prevalence among blood donors at Blood Bank of national health laboratory and the majority of the cases were male under 40 years old. Further studies should be done with inclusion of more samples and using more sensitive technique like Western blot or PCR.
\end{abstract}

Keywords: HTLV1/2; blood bank; seroprevalence; ELISA kit

*Corresponding author: Babbiker Mohammed Taher Gorish, Ph.D. in Medical Microbiology, Department of Microbiology and Immunology - Faculty of Medical Laboratory Science, Omdurman Islamic University, Sudan. Email: qorish456@gmail.com

Received 24 March 2019; Revised 27 May 2020; Accepted 10 June 2020; Published 18 June 2020

Citation: Goris BMT. Human T-cell lymphotropic virus types 1 and 2 antibodies seroprevalence among blood donors at national public health blood bank, Khartoum- Sudan 2019. J Med Sci Res. 2020; 8(3):100-104. DOI: http://dx.doi.org/10.17727/ JMSR.2020/8-14

Copyright: (C) 2020 Goris BMT. Published by KIMS Foundation and Research Center. This is an open-access article distributed under the terms of the Creative Commons Attribution License, which permits unrestricted use, distribution, and reproduction in any medium, provided the original author and source are credited. 


\section{Introduction}

The human T-lymphotropic viruses also known as human T-cell leukemia-lymphoma viruses (HTLV) are RNA group of viruses those belong to retroviruses family. To date, four types of HTLVs (HTLV-1, HTLV-2, HTLV-3, and HTLV-4) identified to cause human disease [1]. HTLV-1, which has six subtypes (A-F) has been implicated in several kinds of diseases, including tropical spastic paraparesis, and as a virus cancer link for leukemia (Adult $\mathrm{T}$ cell leukemia lymphoma) [2]. While HTLV-2, which has four subtypes may be linked to cutaneous T-cell lymphoma [3]. Both viruses are transmitted through blood contact (blood transfusion, injected drug abuse) in addition they can also transmitted through sexual contact with infected person or through breast feeding $[4,5]$.

Both HTLV-1 and HTLV-2 are involved in actively spreading epidemics, affecting 15-20 million people worldwide [6]. With HTLV-1 being the most clinically significant of the two: at least 500,000 of the individuals infected with HTLV-1 eventually develop an often rapidly fatal leukemia, while others will develop a debilitative myelopathy, and yet others will experience uveitis, infectious dermatitis, or another inflammatory disorder. However, HTLV-2 is associated with milder neurologic disorders and chronic pulmonary infections. Moreover, there were no specific illnesses have yet been associated with HTLV-3 and HTLV-4 [6].

Up to 2014 the estimated adult seroprevalence of the HTLV-1 was at least $1-2 \%$ but it can also reach $20-40 \%$ among people aged over 50 years in specific clusters. The main highly endemic areas are the south-western part of Japan, some parts of the Caribbean and its surroundings regions. There are foci in South America, especially in parts of Colombia and French Guyana, some areas of intertropical Africa (such as south Gabon) and in the Middle East (such as the Mashhad region in Iran) and rare isolated clusters in Australia and Melanesia. In Europe, the only country with an endemic HTLV-1 region is Romania. Interestingly and despite different socio-economic and cultural environments, HTLV-1 seroprevalence increases gradually with age, especially in women, in all the endemic areas. The general increase with age may be related to a cohort effect, as is well demonstrated in Japan, while the increase seen in older women might also be due to an accumulation of sexual exposures with age [7-12]. While HTLV-2 subtypes are related to highly specific subpopulations and behaviour like injection drug use [13].

It has been well established that blood transfusion and tissue transplantation may harbors risk for transmission of both HTLV-1,2. This risk may influenced by either the prevalence of the HTLV1,2 infection in the general and donor population or the type of substances of human origin (SoHO) that may contain various numbers of lymphocytes [14]. According to EU Directive, persons with HTLV1,2 infection should be permanently deferred from donation of blood and blood components [14].

In Sudan there was no data about the seroprevalence of the HTLV-1,2 among all populations including blood donors. In addition, the Sudanese blood banks were screened only the presence of HBV, HCV and HIV. Therefore this study was the first of its type in our country that seeking to identify the prevalence of the HTLV-1,2 among blood donors.

\section{Materials and methods}

This study was cross-sectional and it was conducted in the blood bank of the National Public Health Laboratory in Khartoum State. During the period of August to October 2019 a total of 394 blood samples were obtained from blood donors visiting the Blood bank of National Public Health Labortory, both males and females were included.

\section{Specimen's collection and processing}

A volume of $5 \mathrm{ml}$ blood was collected from each patient through venepuncture technique then displaced into a plain container. Each blood sample was centrifuged at $3000 \mathrm{~g}$ for $5 \mathrm{~min}$, and then serum was gently collected into Eppendorf tube and stored at $-20^{\circ} \mathrm{C}$ until the serological analysis.

\section{Specimens analysis}

The samples were analyzed for the presence of anti - HTLV-1 and HLA-2 by a commercially available enzyme-linked immune-sorbent assay [Name Human T-cell lymphotropic Virus antibody, HTLV 1 and 2 (each kit specific for one species) Ab ELISA Kit Cat.No: DEIA079 - Creative Diagnostics, Shirley, NY, US]. The assay was performed following the 
instructions of the manufacturer. Positive and negative controls were included in each assay. According to the information included in the kit's insert, the immunoassay used has a sensitivity and specificity of $100 \%$ and $99.95 \%$ respectively. Each serum samples was examined two time one by HTV-1 specific kit and another time by HTLV-2 specific kit.

\section{Procedure of ELISA test}

All reagents and specimens were settled to reach room temperature. 50 ul of HRP conjugate was added to each well except the blank, then $50 \mu$ of a positive control; negative control and specimen were added to their respective wells. The plate was covered with plate cover and incubated for 60 minutes at $37^{\circ} \mathrm{C}$. By the end of the incubation period, each well was washed 5 times with diluted wash buffer. Finally, 50 $\mu \mathrm{l}$ of chromogen A and chromogen B solutions were added to each well including blank, then the plate was incubated at $37^{\circ} \mathrm{C}$ for 15 minutes. At the end of the incubation $50 \mu \mathrm{l}$ of stop solution was added to each well and the absorbance was measured at $450 \mathrm{~nm}$.

\section{Quality control and calculation of the results}

Reagent, standard, and control were checked for storage, stability, and preparation before starting work. Each micro plate was considered separately when the results were calculated and interrelated; the results were calculated by relating each specimen absorbance $(\mathrm{A})$ to the cut off ( $\mathrm{CO})$ of the plate.

CO value for HTV-1 specific kit was calculated through the equation of $(\mathrm{CO})=\mathrm{NC}+0.18$ where $\mathrm{NC}$ is mean of the three negative controls $=(0.02+0.031+0.01) / 3$ $+0.18=0.20$.

CO value for HTV-2 specific kit was calculated through the equation of $(\mathrm{CO})=\mathrm{NC}+0.18$ where $\mathrm{NC}$ is mean of the three negative controls $=(0.04+0.031+0.01) / 3$ $+0.18=0.25$.

Interpretation of results: Positive more than cut-off value. Negative less than cut-off value.

A method used for data collection: Administrated questionnaire was used to collect patient's data including the gender and age and marital status.

\section{Data analysis}

The data, which were collected from questionnaire and laboratory analysis, were analyzed by SPSS version 15 computerized programs.

\section{Results}

A total of three hundred and ninety four (394) samples were obtained from blood donors participated in this study of which 361 (91.6\%) were males and 33 (8.4\%) were females. The donors ages ranged from 18 to 53 years (median 33 and mode 18 years) and most of them were less than 25 years age. The majority of donors were single $84.2 \%$ while the rest $15.8 \%$ were married (Table 1 ).

Table 1: Demographic and donor baseline characteristics for the study participants.

\begin{tabular}{|c|c|c|}
\hline Character & Frequency & Percentage (\%) \\
\hline \multicolumn{3}{|l|}{ Gender } \\
\hline Male & 361 & 91.6 \\
\hline Female & 33 & 8.4 \\
\hline \multicolumn{3}{|l|}{ Age } \\
\hline$<25$ & 271 & 68.7 \\
\hline $26-40$ & 68 & 17.4 \\
\hline$>40$ & 55 & 13.9 \\
\hline \multicolumn{3}{|l|}{ Marital status } \\
\hline Single & 332 & 84.2 \\
\hline Married & 62 & 15.8 \\
\hline
\end{tabular}

Of the 394 blood donors, four were found to be seropositive for HTLV-1 antibodies giving a prevalence of $1.02 \%$ (Figure 1). While all samples were negative for the HTLV-2 antibodies (Figure 2). Among HTLV-1 positive cases three were male (75\%) while only one female (25\%) was found to be seropositive for HTLV-1 antibodies (Table 2). None of the married donors was found to be seropositive for HTLV-1. The distribution of HTLV-1 antibodies seroprevalence was found to be equal between the group of blood donors who aged $<25$ and the group of who between 26-40 years. While none of those over 40 years have antibody to HTLV-1 (Table 2). 


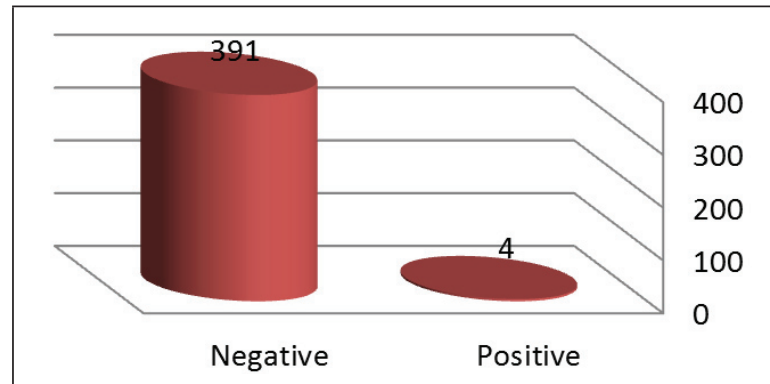

Figure 1: Result of HTLV - 1 serology test.

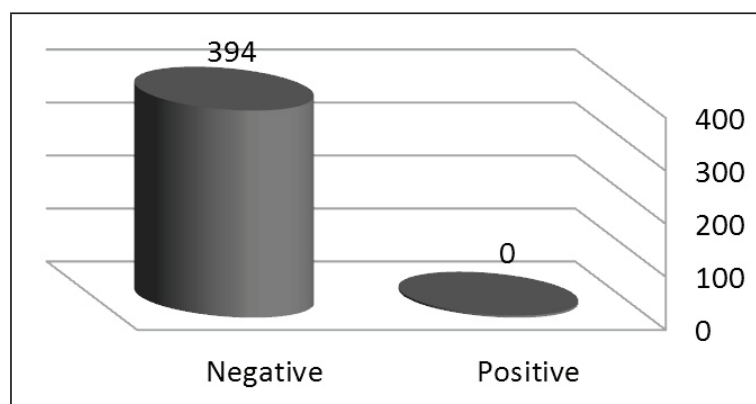

Figure 2. Result of HTLV-2 serology test.

Table 2: HTLV-1 seropositivity versus demographic and donor baseline characteristics for the study participants.

\begin{tabular}{|llcc|}
\hline Character & & Frequency & Percentage (\%) \\
\hline Gender & & $3 / 4$ & 75 \\
& Male & $1 / 4$ & 25 \\
Age & Female & & \\
& & $2 / 4$ & 50 \\
& $<25$ & $2 / 4$ & 50 \\
& $26-40$ & $0 / 4$ & 0 \\
& $>40$ & & \\
Marital status & & $4 / 4$ & 100 \\
& Single & $0 / 4$ & 0 \\
\hline
\end{tabular}

\section{Discussion}

Result obtained by this study shows that the seroprevalence of HTLV-1 and HTLV-2 were 1.02\% and $0 \%$ respectively which is similar to that found among blood donors presenting to blood banks in Mozambique where the seroprevalence of HTLV-1/2 were found to be $0.9 \%$ [15]. However their study was differed from our study in that they confirm their result by Western blot technique instead we use only ELISA technique. The seroprevalence of HTLV$1 / 2$ in this present study is comparatively matched to that estimated internationally in $20141-2 \%$ [13]. However, our result was lower than that obtained in Nigeria in 2011 which was 3.6\% [16]. And higher than that obtained in Uganda which was 0.5\% [17].

In this study, 3 out of 4 HTLV- 1 seropositive donors were males. This is not in conformity with studies that have shown prevalence of HTLV-1 and HTLV-2 to be higher in females as opposed to males, which is related to transmission that is more efficient from men to women during sexual intercourse [18]. The high seroprevalence of HTLV-1 antibodies among male's blood donors than female is most likely due to the higher proportion of males compared with females in this study. Further studies should be done to verify this output.

In this study the HTLV-1 seroprevalence was equally distributed among donors under 25 years and those between 26 to 40 years age. A possible explanation could be that these seropositive donors are sexually active group and may have had sex with a partner that could have been infected with HTLV.

\section{Conclusion}

We conclude that the seroprevalence of HTLV 1/2 were matched to the internationally estimated prevalence among blood donors at Blood Bank of National Health Laboratory and the majority of the cases were male under 40-year-old. This study has a number of limitations. First, the sample size is relatively low and the most participants were male population, which give rise to gender bias. Second, we use ELISA technique, which was less sensitive than molecular technique. Therefore, further studies should be done with inclusion of more samples and using more sensitive technique like Western blot or PCR.

\section{Ethical approval and consent}

Approval was taken from Research Ethic Committee of Omdurman Islamic University and verbal consent was taken from each farm. And all the information's taken were treated confidentially and it was used only for research purposes.

\section{Acknowledgments}

The authors acknowledge the efforts of blood bank staff of Public Health Laboratory for availing their facilities and time for this study. 


\section{Conflicts of interest}

\section{Author declares no conflicts of interest.}

\section{References}

[1] Poiesz BJ, Ruscetti FW, Gazdar AF, Bunn PA, Minna JD, et al. Detection and isolation of type $C$ retrovirus particles from fresh and cultured lymphocytes of a patient with cutaneous T-cell lymphoma. Proc Natl Acad Sci USA. 1980; 77(12): 7415-7419.

[2] Ezra ÈD, Pomerantz RG, Geskin LJ. Infectious agents in cutaneous T-cell lymphoma. J Am Acad Dermatol. 2011; 64(2):423-431.

[3] Roucoux DF, Wang B, Smith D, Nass CC, Smith J, et al. A prospective study of sexual transmission of human $t$ lymphotropic virus (HTLV)-I and HTLV-II. J Infect Dis. 2005; 191(9):1490-1497.

[4] Coovadia HM, Rollins NC, Bland RM, Little K, Coutsoudis A, et al. Mother-to-child transmission of HIV-1 infection during exclusive breastfeeding in the first 6 months of life: an intervention cohort study. Lancet. 2007; 369(9567):11071116.

[5] Thé GD, Kazanji M. An HTLV-I/II vaccine: from animal models to clinical trials? J Acquir Immune Defic Syndr Hum Retrovirol. 1996; 13 Suppl 1:S191-198.

[6] Desrames A, Cassar 0, Gout O, Hermine O, Taylor GP, et al. Northern African strains of human T-lymphotropic virus type 1 arose from a recombination event. J Virol. 2014; 88(17):9782-9788.

[7] Develoux M, Dupont A, Meynard D, Delaporte E. A case of tropical spastic paraparesis associated with HTLV 1 in the Niger Republic. Med Trop (Mars). 1996; 56(1):100-101.

[8] Diop S, Calattini S, Abah-Dakou J, Thiam D, Diakhate L, et al. Seroprevalence and molecular epidemiology of human T-Cell leukemia virus type 1 (HTLV-1) and HTLV-2 in blood donors from Dakar, Senegal. J Clin Microbial. 2006; 44(4):15501554.

[9] Dumas M, Houinato D, Verdier M, Zohoun T, Josse R, et al. Seroepidemiology of human T-cell lymphotropic virus type $1 /$ II in Benin (West Africa). AIDS Res Hum Retroviruses. 1991; 7(5):447-451.

[10] El-Farrash MA, Badr MF, Hawas SA, el-Nashar NM, Imai J, Komoda H, et al. Sporadic carriers of human T-lymphotropic virus type I in northern Egypt. Microbial Immunol. 1988; 32(9):981-984.

[11] El-ghazzawi E, Hunsmann G, Schneider J. Low prevalence of antibodies to HI V-1 and HTLV-I in Alexandria, Egypt. AIDS Forsch. 1987; 2(11):639.

[12] Anyanwu NCJ, Ella EE, Ohwofasa A, Aminu M. Re-emergence of human T-lymphotropic viruses in West Africa. Braz J Infect Dis. 2018; 22(3):224-234.

[13] Urwijitaroon Y, Barusrux S, Puapairoj C, Romphruk A, Khampeera P, Seroepidemiology of HTLV-1 infection in northeast Thailand: four year surveillance. Journal of the Medical Association of Thailand: a four year surveillance. J Med Assoc Thai. 1997; 80 Suppl 1:S102-S105.

[14] Wang $\mathrm{CH}$, Chen $\mathrm{CJ}, \mathrm{Hu} \mathrm{CY}$, You SL, Chu CT, et al. Seroepidemiology of human T-cell lymphotropic virus type I infection in Taiwan. Cancer Res. 1988; 48(17):5042-5044.

[15] Gudo ES, Abreu CM, Mussa T, Augusto ADR, Otsuki K, et al. Serologic andmolecular typing of human T-lymphotropic virus among blood donors in Maputo City, Mozambique. Transfusion. 2009; 49(6):1146-1150.
[16] Terry AA, Olusoga OD, Oluremi AS, Okanlawon BM, Uche LN, et al. Seroprevalence of HTLV-I/II amongst blood donors in Osogbo, Nigeria. Sudan J Med Sci. 2011; 6(3):177-182.

[17] Tweteise PU, Natukunda B, Bazira J. Human T-Cell Lymphotropic Virus Types 1 and 2 Seropositivity among Blood Donors at Mbarara Regional Blood Bank, South Western Uganda. Leukemia Research and Treatment. 2016; Article ID 1675326.

[18] de Lima WMG, Esteves FAM, Torres MCMR, Pires ESF. Prevalence of human T-cell lymphotropic virus types 1 and 2 in blood donors of the Caruaru Blood Center (Hemope). Rev Bras Hematol Hemoter. 2013; 35(4):268-271. 